\title{
A Study of Cultural Philosophy in the Reform of College English Teaching
}

\author{
ZHANG Xiaoyu ${ }^{1, \text { a }}$
}

${ }^{1}$ Wuhan Polytechnic, Wuhan 430074,China

azhangxiaoyu@126.com

Keywords: College English, teaching and learning reform, cultural philosophy

\begin{abstract}
College English is an integral part of the undergraduate curriculum system. College English teaching is one of the important ways to cultivate and enhance college students' cultural literacy. With the development of society and the need of external communication, the voice of College English teaching reform has hardly ceased. 2004 "College English Curriculum Requirements (for Trial Implementation)" promulgated, the significance of the study of College English teaching is highlighted. The reality of College English Teaching in the subject, content, process, evaluation and other aspects still focus on instrumental orientation, resulting in "lost," a starting point process covered "and" dislocation ", leading to the neglect of results of College English the teaching of" cultural communication "and" cultural understanding "of the phenomena and problems. From the perspective of cultural philosophy, this study analyzes the practical problems of College English teaching, and holds that the main reason for these problems lies in the tool rationality orientation of College English teaching. To solve this problem, this study from the social dominant cultural values of the evolution process, the world of higher education reform and development trend of teaching culture, research paradigm perspective, criticizing the traditional college English teaching emphasis on instrumental teaching and neglect the humanities, advocate and the tool of integration, from the teaching objectives, contents, implementation and evaluation of teaching elements to the construction of College English teaching picture from the perspective of cultural philosophy, to provide theoretical support for quality and improve the level of College English teaching. This study uses literature method, survey method, action research method, case study method, observation method, comparative study method and cross cultural analysis, instrumental performance on College English teaching, humanistic appeal of College English teaching from the perspective of cultural philosophy, problems of College English teaching and learning objectives, content, implementation and evaluation of in-depth study.
\end{abstract}

\section{Introduction}

College English teaching is an important part of our foreign language education. College English, as one of the compulsory courses of college students, is used as the first foreign language in most universities. The scale of English learners in China's colleges and universities is large, and the teaching involves a wide range, which has a great influence. In twenty-first Century, with the economic globalization, China has become more and more closely connected with the world. In 2001, China successfully joined the World Trade Organization (WTO). In 2008, China successfully hosted the Olympic Games. In 2010 Shanghai hosted World Expo. These marks China's opening to the world with a more open stance. As early as last century, China proposed to build China into a moderately developed country by the middle of the twenty-first Century, and to realize the great 
rejuvenation of the Chinese nation. To achieve this goal, we must carry out the coordinated development of scale, structure and efficiency, and the quality of College English teaching must be improved, which is determined by the importance of College English teaching. As early as 1978, Mr. $\mathrm{Xu}$ Guozhang made a call to the outside world. The language community "takes the primary task of foreign language teaching - fostering the great army of science and culture that understands both professional and foreign language in all walks of life -". In the era of political polarization, economic globalization and cultural pluralism, our college students should strengthen their foreign language learning and learn foreign languages, so as to meet the needs of national economic development and external communication. However, up to now, there is still a problem of "time consuming and inefficient" in the teaching of College English in China. After the years of college study, students still can not communicate effectively in English. College English teaching is facing great challenges. In addition, with the development of society, the training of talents of all-round development is becoming a hot topic in the educational field. This is a new requirement for the training of talents in Colleges and universities, that is, the all-round development. In addition to carrying out scientific quality education for college students, colleges and universities should also educate their humanity quality, and integrate the two elements together, so as to jointly promote the improvement of College Students' comprehensive quality.

\section{The Connotation of College English}

The term "College English" first came from the "College English" used by the English expert, Professor Hu Wenzhong, for the name of non professional English textbooks. It refers to the English course offered to non foreign language majors, formerly known as public English. In November 1986, the Chinese Institute of foreign language teaching was renamed the College of foreign language teaching, and the public English was also renamed College English accordingly. Later, "College English" has gradually been considered to be the opposite of "professional English" for non - foreign language majors to learn English. From here we can see that college English is a compound word, the first is not the University, middle school and primary school, decided this course of study students are college students, but also for non English major undergraduate students; the second is English, non English majors to learn English but not other language subjects. Therefore, I define College English as a basic course for non foreign language majors to enhance their language knowledge, language skills and humanistic quality. In order to understand college English more clearly, it is necessary to understand the problems of these aspects: the characteristics of English in the type of language. Language as human communication and dissemination of information, plays an important role in the development of human history, people can use the language to save and transfer the achievements of human civilization, and also is the national language symbol, generally speaking, each nationality has its own language. Human has abundant language is an important feature of the human from the animal, some animal although it can roar through the exchange of information, but this is just the primary animal instinct, unlike the human language contains rich thoughts and feelings, therefore, the origin of human language is a key step towards the development of adult human. As a kind of human language, English has a special position in the process of information exchange and cultural communication all over the world. Among the languages of the world, English has the following features: widely used. English speaking countries are distributed in all continents of the world. Compared with other languages, English is the most widely used language in the world today. There are two meanings in this area: one is the large number of people who use English; the two is that English is widely used in life. In the report of the world's major languages, distribution and application force published by the United 
Nations in 2005, English ranks first. Its population reaches more than 500 million, and English learners at least 1 billion or more. This indicates that English plays an important role in world communication. Since the reform and opening up, due to the needs of foreign exchanges, China's demand for foreign language talents is increasing rapidly, the English talent is our most in need of talent, our country foreign exchange is the main English speaking countries, so the cultivation of English talents is an important guarantee for our opening.

\section{The Characteristics of College English Compared with Middle School English and Primary English}

College English is a required course to improve our national English level and promote communication and cooperation with the world. Compared with middle school English and primary school English, College English embodies many new characteristics: more emphasis on training students' communicative competence. The goal of College English teaching is to cultivate students' Comprehensive English application ability, especially listening and speaking skills, enabling them to communicate effectively in oral and written English in future work and social interaction. Round relative to the primary and middle school English, College English pay more attention to the cultivation of students' communicative ability, this is because communication is our ultimate goal of learning English, but also reflects the important sign of one's English level, and college graduates are facing employment, the employer is more valued graduates' practical ability to use English, therefore improve their ability of cross-cultural communication is the inevitable choice, while the students are facing the entrance, it pays more attention to the students' mastery of basic skills, improve test scores is the primary task of students, while the proportion in the exam hearing oral exam for relatively light, therefore, to improve the students' reading and writing ability of students the fundamental way to improve performance. Therefore, in this sense, College English pay more attention to the cultivation of students' communicative ability. More attention to training Students' self-learning ability. Autonomous learning is based on students as the main body of learning, through independent analysis, exploration, practice, questioning, creativity and other methods to achieve learning goals, learning self-reliance, self-reliance and self-discipline are three basic characteristics of "autonomous learning". In the way of learning, College English pays more attention to students' autonomous learning. From the perspective of psychology, the self-control ability of college students is stronger than the primary and middle school students, and the students can accomplish their learning tasks more independently. In reality, college students learn more by themselves, few teachers force students to learn, while primary and secondary school English tends to control students, and teachers dominate students' English learning. Therefore, compared with the primary and secondary school English, College English pays more attention to the students' self-learning ability.

\section{The Value of College English Teaching}

"College English one refers to an English course for non - foreign language majors." "Curriculum requirements" said: "College English course is a required basic course for college students." University English is a foreign language teaching theory as a guide to English language knowledge and practical skills of learning strategies and intercultural communication as the main content, and a variety of teaching methods and teaching means teaching system." "Curriculum requirements" put forward the principle of carrying out the guidance of classification and teaching students in accordance with their aptitude so as to meet the practical needs of individualized teaching. From the 
aspects of listening, speaking, reading, writing, translating and communication strategies, it puts forward general, higher and higher requirements, so as to encourage students to adjust their learning goals to higher requirements or higher requirements according to their learning situations. According to the above discussion, we define the value of College English teaching as the characteristics that college English teaching meets the needs of the subject (individual and Society). According to the characteristics of teaching value and the requirements of College English to meet the needs of society and individual subjects, the value of College English teaching is reflected in the following aspects: first, the value of language knowledge and applied skills.

Language knowledge and applied skills are the basic objectives of English teaching. Without the basic skills of language, everything inside the language can not be grasped, mastered and transformed. The former is the basis of the latter, while the latter is the purpose of the former. On the one hand, language knowledge and language skills are the effective carriers of the ability of language use, which must be paid attention to. It is not the same as "the moon in the water, the mirror flower in the mirror" to leave the knowledge of the language and the acquisition of the language skills. Therefore, some effective ways and means of teaching in the past are should confidently insist, such as dictation, dictation, recitation. For some basic knowledge, we should make great efforts to make good efforts and implement it. On the other hand, the starting point and end result of learning language knowledge and acquiring language skills is to enable students to get the comprehensive ability to use language. It must serve and obey the cultivation of students' language proficiency. In this sense, teaching can not only be knowledge, but can not let classroom teaching stay on the level of knowledge teaching. Secondly, the value of cultural consciousness. Language is the symbol and carrier of society and culture. It is like a mirror. The language of different nationalities reflects and records the cultural features of different ethnic characteristics. It is necessary for the intercultural communicators to be the language and culture of the target language countries, which requires the accumulation of time and life experience. Owing to the differences between the two kinds of culture value, the process of translation and the loss of the English language itself, many aspects of the dynamic development may lead to cross-cultural communication obstacles and mistakes, so we should not only learn to respect the characteristics of different languages, and use different cultures to learn. In cross-cultural communication, we should be familiar with the language features and cultural background, grasp the pulse of the times, exercise language skills, from many aspects to consider the language communicative effect and communicative way, can more accurately understand and grasp the use of English, achieve the purpose of cross culture communication. Again, the value of emotional attitude. Emotional attitude refers to factors related to interest, motivation, self-confidence, will and spirit of cooperation, which influence students' learning process and learning effect, as well as the consciousness of motherland and international perspective gradually formed in the process of learning.

\section{Understanding Evaluation}

For a long time, in the process of College English teaching evaluation in China, evaluators regard English teaching evaluation as a special cognitive process. This epistemological teaching evaluation emphasizes the acquisition and possession of knowledge in the process of English learning. In this knowledge oriented teaching evaluation, College English teaching has evolved into a typical teaching mode of instillation. The connotation of richness and diversity in English teaching activities has been engulfed by single and definite epistemology. The main factor that leads to this phenomenon is the direction of the fixed thinking of epistemology. Of course, the epistemology of teaching evaluation oriented concept has its rationality, but from the overall harmonious 
development dimension, the teaching evaluation in order to understand the theory oriented view of no matter how perfect, are difficult to compensate for the way of thinking in the process of teaching evaluation, finally still can not solve the disadvantages. So in College English teaching evaluation has to be fundamentally resolved, we must proceed from the angle of hermeneutics, the process of teaching evaluation as a deeper understanding of the process rather than a simple process of epistemology, in order to build a college English teaching evaluation in order to understand the guidance of the concept of. The concept of comprehensible teaching evaluation is the reflection and criticism of the current epistemology oriented teaching evaluation view, and it is a real challenge to the teaching evaluation view of epistemology. Finally, in the evaluation of understanding teaching, we should pay more attention to the generative characteristics of teaching evaluation. Because in a sense, the process of understanding is a process of continuous generation and continuous development. For the understanding of teaching evaluation, generative is also an important feature. It is mainly manifested in the generative nature of teaching evaluation standards, the generation of teaching evaluation methods, and the creation of teaching evaluation results. From the above discussions, we can see that the evaluation of comprehensible teaching is not only conducive to the professional development of teachers, but also conducive to the common dialogue and communication between teachers and students, so as to promote students' overall, harmonious and healthy growth.

\section{References}

[1] Static cultural introduction in Higher Vocational English teaching application [J] English Square 2012.

[2] Yellow Qiuchang in College English teaching reflection [J] humanities education examination weekly 2010 (53).

[3] G.Q. Analysis of current situation and reform strategy of College English Teaching in China [J]; China Education Innovation Herald; 201205.

[4] W.G.G. Analysis of the attitude of learner autonomy in College English [J]; Journal of the Jilin Institute of Education (the next ten days); 062013.

[5] L.S. The application of the environmental theory of two language acquisition in College English teaching [J]; the study of curriculum education; the 07 phase of 2014.

[6] Y.G.Z. Introspection on College English teaching reform [J] from New Oriental CET training; Journal of Xinxiang College; 032014. 